Jean-François Pouliot Richard Béliveau

\title{
Modifications post-traductionnelles des protéines par les lipides
}

Les modifications covalentes des protéines par les lipides ont d'abord été associées à un rôle passif d'ancrage à la membrane, puis on a identifié des modifications posttraductionnelles des protéines par des lipides qui semblent jouer un rôle important dans l'activité biologique de nombreuses protéines. Elles sont de deux types: la palmitoylation et l'isoprénylation. La première est réversible et les protéines modifiées se localisent à la face interne de la membrane plasmique ou au niveau du réticulum endoplasmique. La seconde est irréversible et on retrouve les protéines modifiées dans plusieurs compartiments cellulaires, tels la membrane plasmique ou le noyau. La palmitoylation s'effectue principalement sur des résidus cystéines, mais aucune séquence consensus n'a pu être identifiée. En revanche, l'isoprénylation est très sélective et seules des séquences C-terminales spécifiques contenant une ou deux cystéines sont reconnues. Ces deux modifications jouent un rôle important dans la régulation de protéines telles que le récepteur $\beta_{\mathrm{z}}$-adrénergique et les protéines de la famille des produits des protooncogènes ras. Il ne s'agit pas là d'exemples isolés, les modifications post-traductionnelles des protéines par les lipides apparaissent aujourd'hui comme une voie importante du contrôle de l'activité cellulaire.

\begin{abstract}
ADRESSES
J.F. Pouliot: Laboratoire de membranologie, Groupe de recherche en biothérapeutique moléculaire, université du Québec à Montréal. R. Béliveau : groupe de recherche en transport membranaire, université de Montréal. C.P. 8888, succ. A, Montréal, Québec, Canada H3C 3P8.
\end{abstract}

TIRÉS A PART

J.F. Pouliot.

$m / s n^{\circ} 1$ vol. 10, janvier 94 es modifications des protéines par des lipides ont été mises en évidence il y a plusieurs années, lors des solubilisations de protéines par des solvants organiques [1]. Ce phénomène avait été alors considéré comme très limité. Aujourd'hui, on connaît quatre types principaux de modifications covalentes des protéines par des lipides (figure 1): (1) la myristoylation, qui consiste en l'ajout d'un acide myristique via une liaison amide sur une glycine située en position N-terminale des protéines [2, 3] ; (2) la glypiation, par ajout d'un groupement glycosylphosphatidylinositol (GPI) sur l'acide aminé C-terminal des protéines [4] ; (3) la palmitoylation, qui consiste en l'ajout d'un acide palmitique (AP) sur certains résidus cystéines (Cys) [4, 5] ; (4) l'isoprénylation, qui est caractérisée par l'ajout d'un farnésyl ou d'un géranylgéranyl sur une cystéine 


\section{RÉFÉRENCES}

1. Folch PJ, Iees M. Proteolipids, a new type of tissue lipoproteins. Their isolation from brain. J Biol Chem 1951 ; 191 : 807-17.

2. Gordon JI, Duronio RJ, Rudnick DA, Adams SP, Gokel GW. Protein Nmyristoylation. J Biol Chem 1991; 266 : 8647-50.

3. Boutin J. La N-myristoyl transférase, carrefour entre virologie et oncologie: une nouvelle voie d'accès des activités anticancéreuses et des antiviraux d'un genre nouveau. médecine/sciences $1993 ; 9$ : 684-92.

4. Saltiel AR, Ravetch J, Aderem AA. Functional consequences of lipid-mediated protein-membrane interactions. Biochem Pharmacol 1991; 42 : 1-11.

5. James G, Olson EN. Fatty acylated proteins as components of intracellular signaling pathways. Biochemistry 1990; 29 : 2623-34.

6. Glomset JA, Gelb MH, Farnsworth CC. Prenyl proteins in eukaryotic cells : a new type of membrane anchor. Trends Biochem Sci $1990 ; 15: 139-42$.

7. Clarke S. Protein isoprenylation methylation at carboxyl-terminal cysteine residues. Annu Rev Biochem 1992; 61 : 355-86.

8. Olson EN, Towler DA, Glaser L. Specificity of fatty acid acylation of cellular proteins. J Biol Chem 1985; 260 : 3784-90.

9. Schmidt MFG, Schlesinger MJ. Relation of fatty acid attachment to the translation maturation of vesicular stomatitis and sindbis virus membrane glycoproteins. J Biol Chem 1980 ; 255 : 3334-9.

10. Wilcox CA, Olson EN. The majority of cellular fatty acid acylated proteins are localized to the cytoplasmic surface of the plasma membrane. Biochemistry 1987; 26 : 1029-36.

11. Schmidt M, Schmidt MFG, Rott $R$ Chemical identification of cysteine as palmitoylation site in a transmembrane protein (semliki forest virus El). J Biol Chem $1988 ; 263$ : 18635-9.

12. Okubo K, Hamasaki N, Hara $\mathrm{K}$, Kageura M. Palmitoylation of cysteine 69 from the COOH-terminal of band 3 protein in the human erythrocyte membrane. Acylation occurs in the middle of the consensus sequence of F-I-IICIAVL found in band 3 protein and $\mathrm{G} 2$ protein of rift valley fever virus. J Biol Chem 1991; 266 16420-4.

13. Berger M, Schmidt MFG. Cell-free fatty acid acylation of semliki forest viral polypeptides with microsomal membranes from eukaryotic cells. J Biol Chem 1984; 259 7245-52. située en position C-terminale de certaines protéines $[6,7]$. Ces modifications peuvent être, soit cotraductionnelles, soit post-traductionnelles (Tableau I).

\section{Modifications co-traductionnelles}

\section{Myristoylation et glypiation}

Le myristate est un acide gras saturé de 14 carbones qui peut être transféré sur les glycines N-terminales de certaines protéines via la formation d'une liaison amide avec le groupement $\alpha$-aminé [2-4]. La myristoyla- tion est effectuée par une $\mathrm{N}$ myristoyltransférase présentant une très grande spécificité pour le myristate et reconnaissant des séquences d'acides aminés bien déterminées. Les protéines myristoylées sont notamment impliquées dans la signalisation intracellulaire. Ainsi, certaines tyrosine kinases (p60 src $)$, la sous-unité catalytique de la protéine kinase A et la sous-unité $\alpha$ de nombreuses protéines $G$ sont myristoylées [3, 4]. La myristoylation est également impliquée dans l'attachement à la membrane de nombreuses protéines virales [2]. La myristoy-

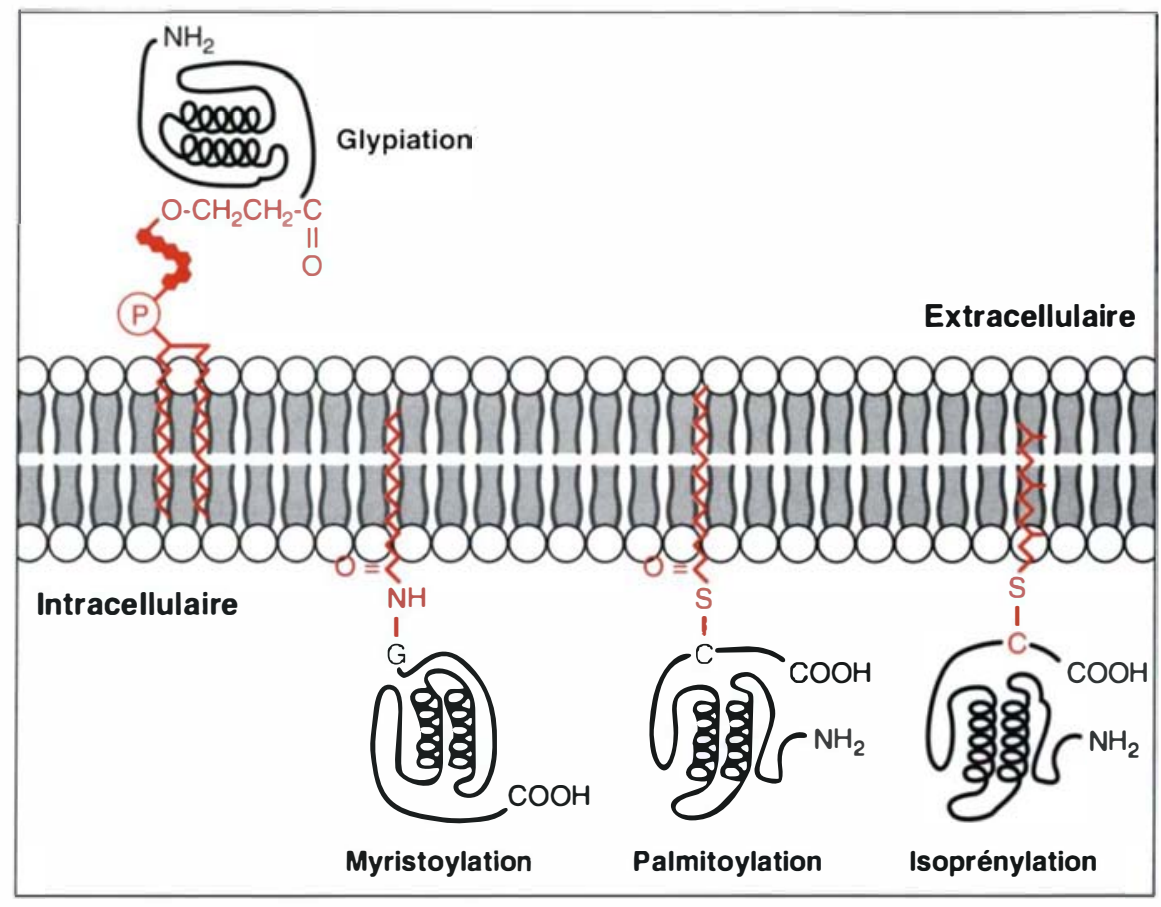

Figure 1. Modifications covalentes des protéines par les lipides. La glypiation, qui consiste en l'ajout d'un groupement glycosyl phosphatidylinositol sur la portion C-terminale des protéines, est destinée à des protéines se retrouvant à la surface externe des cellules. La myristoylation, qui consiste en l'ajout $d^{\prime}$ 'un acide myristique via une liaison amide sur une glycine située en position $\mathrm{N}$-terminale des protéines, est destinée à des protéines se retrouvant au niveau de plusieurs compartiments intracellulaires. Ces deux premières modifications sont co-traductionnelles et permanentes. Deux autres modifications des protéines par des lipides sont post-traductionnelles. La palmitoylation, qui consiste en l'ajout d'un acide palmitique sur les résidus cystéines de certaines protéines, est destinée à des protéines se retrouvant principalement à la surface interne de la membrane plasmique. Cependant, contrairement à la myristoylation, la palmitoylation est une réaction réversible. L'isoprénylation, qui entraîne l'ajout d'un farnésyl ou d'un géranylgéranyl sur une cystéine située en position $C$-terminale de certaines protéines, peut non seulement favoriser des interactions entre protéine et membrane, mais également des interactions protéine-protéine. 
lation s'effectue à la fin de la synthèse protéique et les protéines myristoylées sont retrouvées dans divers compartiments cellulaires (Tableau I). Cette réaction doit être co-traductionnelle car elle est complètement abolie par l'ajout d'inhibiteurs de la synthèse protéique.

La glypiation est classée à la fois comme co et post-traductionnelle [4]. Cette modification est impliquée dans l'attachement à la membrane de nombreuses enzymes hydrolytiques et antigènes qui sont retrouvés généralement sur la face externe des cellules ([4], $\mathrm{m} / \mathrm{s} n^{\circ} 10$, vol. 9, p. 1130). L'ajout du groupement GPI se fait au niveau du réticulum endoplasmique, tout à la fin de la synthèse protéique [4]. L'ambiguité se situe au niveau de la dernière étape du processus traductionnel impliquant le clivage du peptide signal et l'ajout du groupement GPI. Comme le clivage est effectué avant l'ajout du groupement GPI, la modification peut être considérée comme post-traductionnelle. Cependant, ces deux réactions seraient catalysées par la même enzyme [4], la glypiation pourrait donc également être considérée comme co-traductionnelle.

\section{Modifications post-traductionnelles}

\section{Palmitoylation des protéines}

\section{- Synthèse}

L'acide palmitique est un acide gras saturé de 16 carbones qui peut être transféré sur les cystéines de certaines protéines (figure 2) via l'action d'une palmitoyltransférase $[4,5]$. La liaison de l'acide palmitique aux protéines se fait en général par une liaison thioester sensible à l'hydroxylamine et à la potasse méthanolique [8]. L'ajout du palmitate s'effectue au niveau post-traductionnel, 10 à 20 minutes après la synthèse protéique [9]. Les protéines palmitoylées (Tableau II) semblent ciblées principalement vers la face interne de la membrane plasmique [10]. On n'a pas identifié de séquence consensus d'acides aminés formant le site de palmitoylation; on a seulement montré que la palmitoylation s'effectue en général sur des cystéines localisées sur une portion de la protéine proche de la membrane plasmique [11]. Récemment, une séquence commune à une protéine virale et à la bande 3 des érythrocytes a été identifiée comme site de palmitoylation [12]. La synthèse de peptides, à partir de cette séquence, devrait permettre de purifier la palmitoyltransférase. Bien que certains cas de palmitoylation autocatalytique aient été rapportés [13-15], plusieurs études ont démontré la présence d'une protéine catalysant le transfert de palmitate; sur les protéines [13, 14]. L'enzyme responsable du transfert du palmitate a d'abord été identifiée au niveau du cis-Golgi [16], puis partiellement purifiée à partir de la muqueuse gastrique où cette enzyme reste associée à la fraction du Golgi [14]. Cependant, la présence d'une palmitoyltransférase a également été démontrée au niveau de la membrane plasmique [17]. La spécificité de la palmitoyltransférase n'est pas absolue pour le palmitate, elle peut catalyser le transfert de substrats ayant de plus longues ou plus courtes chaînes carbonées [13]. Une autre enzyme catalysant la réaction inverse, soit une acylestérase, a également été identifiée [18].

\section{- Recyclage et modulation}

La présence de deux enzymes catalysant des réactions inverses peut expliquer le recyclage rapide du pal-

Tableau I

CARACTÉRISTIQUES DES MODIFICATIONS COVALENTES DES PROTÉINES PAR LES LIPIDES

\begin{tabular}{|c|c|c|c|c|c|c|}
\hline Modification & Site & Stade & Type de liaison & Localisation & Réversibilité & Réf. \\
\hline Glypiation & $\begin{array}{l}\text { Acide aminé } \\
\text { C-terminal }\end{array}$ & Co-traductionnel & $\begin{array}{l}\text { Amide } \\
\text { (COOH et éthanolamine) }\end{array}$ & $\begin{array}{l}\text { Extracellulaire ou } \\
\text { lumière des organites }\end{array}$ & NON & [4] \\
\hline - Farnésylation & $\begin{array}{l}\text { Cys } \\
\text { C-terminal } \\
(C X X X)^{*}\end{array}$ & Post-traductionnel & $\begin{array}{l}\text { Thioéther } \\
\text { (SH et isoprényl-PP) }\end{array}$ & Multiple intracellulaire & NON & {$[6,7]$} \\
\hline $\begin{array}{l}\text { - Géranylgéra- } \\
\text { nylation }\end{array}$ & $\begin{array}{l}\text { Cys } \\
\text { C-terminal } \\
(C \times X X)^{*}\end{array}$ & Post-traductionnel & $\begin{array}{l}\text { Thioéther } \\
\text { (SH et isoprényl-PP) }\end{array}$ & Multiple intracellulaire & NON & {$[6,7]$} \\
\hline & $\begin{array}{l}\text { C-terminal } \\
\text { (XCC } \\
\text { ou } C X C)^{*}\end{array}$ & Post-traductionnel & $\begin{array}{l}\text { Thioéther } \\
\text { (SH et isoprényl-PP) }\end{array}$ & Multiple intracellulaire & $?$ & {$[6,7]$} \\
\hline Myristoylation & $\begin{array}{l}\text { Gly } \\
\mathrm{N} \text {-terminal }\end{array}$ & Co-traductionnel & $\begin{array}{l}\text { Amide } \\
\left(\mathrm{NH}_{2} \text { et myristate }\right)\end{array}$ & $\begin{array}{l}\text { Face interne de la } \\
\text { membrane plasmique, } \\
\text { noyau, reticulum endo- } \\
\text { plasmique, appareil de } \\
\text { Golgi et cytoplasme }\end{array}$ & NON & [2] \\
\hline Palmitoylation & Cys & Post-traductionnel & $\begin{array}{l}\text { Thioester } \\
\text { (SH et palmitate) }\end{array}$ & $\begin{array}{l}\text { Face interne de la } \\
\text { membrane plasmique, } \\
\text { reticulum } \\
\text { endoplasmique }\end{array}$ & OUI & {$[4,5]$} \\
\hline
\end{tabular}

Les données contenues dans ce tableau sont tirées des références [2-7].

* $C=C y s, X=n^{\prime i m p o r t e ~ q u e l ~ a c i d e ~ a m i n e ́ ; ~} P P=$ pyrophosphate.

$\mathrm{m} / \mathrm{s} n^{\circ} 1$ vol. 10 , janvier 94 
14. Slomiany A, Liau YH, Takagi A, Laszewicz W, Slomiany B. Characterization of mucus glycoprotein fatty acyltransferase from gastric mucosa. J Biol Chem 1984; 259: $13304-8$

15. Bizzozero OA, McGarry JF, Lees MB. Autoacylation of myelin proteolipid protein with acyl coenzyme A.J Biol Chem 1987; 262 : 13550-7.

16. Quinn P, Griffiths G, Warren G. Dissection of the Golgi complex II. Density separation of specific Golgi functions in virally infected cells treated with monensin. J Cell Biol 1983; 96 : 851-6.

17. Hancock JF, Magee AI, Childs JE, Marshall CJ. All ras proteins are polyisoprenylated but only some are palmitoylated. Cell 1989; 57: 1167-77.

18. Berger M, Schmidt MFG. Characterization of a protein fatty acylesterase present in microsoma membranes of diverse origin. J Biol Chem 1986; 261 : 14912-8.

19. Staufenbiel M. Ankyrin-bound fatty acid turns over rapidly at the erythrocyte plasma membrane. Mol Cell Biol 1987; 7 2981-4.

20. Magee AL, Gutierrez L, Marshall CI Hall A. Dynamic fatty acylation of p21N ras. EMBO J 1987 ; 6 : 3353-7.

21. James G, Olson EN. Identification of a novel fatty acylated protein that partitions between the plasma membrane and cyto sol and is deacylated in response to serum and growth factor stimulation. J Biol Chem 1989 ; $264: 20998-1006$

22. Jochen A, Hays J, Lianos E, Hager S. Insulin stimulates fatty acylation of adipocyte proteins. Biochem Biophys Res Commun 1991; 177 : 797-801.

23. Huang EM. Agonistenhanced palmitoylation of platelet proteins. Biochim Biophys Acta 1989; 1011: 134-9.

24. Moffett S, Mouillac B, Bonin H, Bouvier $M$. Altered phosphorylation and desensitization patterns of a human $\beta_{2}$-adrenergic receptor lacking the palmitoylated Cys 341. EMBO J 1993; 12 : 349-56.

25. Alvarez E, Girones N, Davis RJ. Inhibition of the receptor-mediated endocytosis of diferric transferrin is associated with the covalent modification of the transferrin receptor with palmitic acid. J Biol Chem $1990 ; 265: 16644-5$

26. Sudo Y, Valenzuela D, Beck-Sickinger AG, Fishman MC, Strittmatter SM. Palmitoylation alters protein activity: blockade of Go stimulation by GAP-43. EMBO J 1992 ; 11 : 2095-102.
27. Christgau S, Aanstoot HJ, Schierbeck $\mathrm{H}$, Begley K, Tullin S, Hejnaes K, Baekkeskov S. Membrane anchoring of the autoantigen GAD65 to microvesicles in pancreatic $\beta$-cells by palmitoylation in the $\mathrm{NH}_{2}$ terminal domain. J Cell Biol 1992 ; 118: 309-20.

28. Rilling HC, Breunger E, Epstein WW, Crain PF. Prenylated proteins: the structure of the isoprenoid group. Science 1990 257 : 318-20.

29. Gutierrez L, Magee AI, Marshall CJ Hancock JF. Post-translational processing of p21ras is two-step and involves carboxylmethylation and carboxy-terminal proteolysis. EMBO J 1989 ; 8 : 1093-8.

30. Gingras D, Boivin D, Bilodeau D, Pelletier J, Béliveau R. Les protéines carboxyméthyltransférases des eucaryotes: deux classes distinctes d'enzymes. médecine/sciences $1994 ; 10$ : 55-64

31. Epstein WW, Lever D, Leining LM, Bruenger E, Rilling HC. Quantitation of prenylcysteines by selective cleavage reaction. Proc Natl Acad Sci USA 1991; 88 . 9668-70.

32. Inglese J, Glickman JF, Lorenz W, Caron MG, Lefkowitz RJ. Isoprenylation of a protein kinase. J Biol Chem 1992; 267 : 1422-5.

33. Ohguro H, Fukada Y, Takao T, Shimonishi Y, Yoshizawa T, Akino T. Carboxyl methylation and farnesylation of transducin $\gamma$-subunit synergistically enhance its coupling with metarhodopsin II. EMBO 1991 ; 10 : 3669-74.

34. Qin N, Pittler SJ, Baehr W. In vitro isoprenylation and membrane association of mouse rod photoreceptor cGMP phosphodiesterase $\alpha$-and $\beta$ subunits expressed in bacteria. J Biol Chem 1992; 267: 8458-63.

35. Anderegg RJ, Betz R, Carr SA, Crabb JW, Duntze W. Structure of Saccharomyces cerevisiae mating hormone a-factor: identification of S-farnesyl cysteine as a structural component. J Biol Chem 1988; 263 : 18236-40.

36. Reiss Y, Seabra MC, Armstrong SA Slaughter CA, Goldstein JL, Brown MS Nonidentical subunits of p21H-ras farnesyltransferase. J Biol Chem 1991; 266 : 10672-7.

37. Yokoyama K, Goodwin GW, Ghomashchi F, Glomset JA, Gelb MH. A protein geranylgeranyltransferase from bovine brain : implications for protein prenylation specificity. Proc Natl Acad Sci USA 1991; 88 : 5302-6.

38. Mumby SM, Casey PJ, Gilman AG Gutowski S, Sternweis PC. G protein $\psi$ subunits contain a 20 carbon isoprenoid. Proc Natl Acad Sci USA 1990; 87 : 5873-7. mitate observé pour de nombreuses protéines, dont celles des membranes érythrocytaires [19]. Dans ce tissu, la demi-vie de liaison de l'acide palmitique varie entre 30 minutes et 3 heures. Plus spécifiquement, la demi-vie de liaison de l'acide palmitique à l'ankyrine est de 50 minutes [19]. Les produits de la famille des proto-oncogènes ras (p21), dont l'expression est ubiquitaire, ont une demi-vie de liaison de l'acide palmitique de 20 minutes [20]. Tous ces exemples démontrent la nature réversible de la liaison de l'acide palmitique.

La liaison et le recyclage du palmitate peuvent être réglés par plusieurs facteurs. Ainsi, une protéine palmitoylée de $64 \mathrm{kDa}$ associée à la membrane plasmique est dépalmitoylée et se retrouve dans le cytoplasme de cellules musculaires après ajout de sérum à la culture cellulaire [21]. L'ajout d'insuline à une culture d'adipocytes entraîne l'augmentation de la palmitoylation d'une protéine de $80 \mathrm{kDa}$ [22]. De même, l'ajout de thrombine à une suspension de plaquettes entraîne la palmitoylation d'une protéine de $38 \mathrm{kDa}$, simultanément à l'agrégation des plaquettes [23]. L'incorporation de palmitate est proportionnelle au taux d'agrégation des plaquettes, ce qui permet de supposer que la palmitoylation est impliquée dans ce processus.

\section{- Rôles}

On a identifié de nombreuses protéines palmitoylées. Quelques-uns des rôles joués par la palmitoylation dans la régulation des fonctions de ces protéines sont énumérés dans le Tableau II. Dans la plupart des cas, la palmitoylation entraîne l'association d'une protéine, ou d'une portion de la protéine, à la membrane plasmique [3], permettant à la protéine d'aller exercer son action au niveau de la membrane [17] (figure 2). La présence d'un palmitate peut également modifier son activité, comme c'est le cas pour le récepteur $\quad \beta_{2}$-adrénergique [24]. Pour ce récepteur, la perte du palmitate entraîne l'exposition de sites de phosphorylation menant à l'inactivation du récepteur [24]. L'intérêt de la palmitoylation réside dans son 
Tableau II

EXEMPLES DE RÔLES JOUÉS PAR LA PALMITOYLATION

Protéine

Rôle de la palmitoylation
Référence

[14]

[19]

Interaction dynamique avec la membrane plasmique

[26] [27]

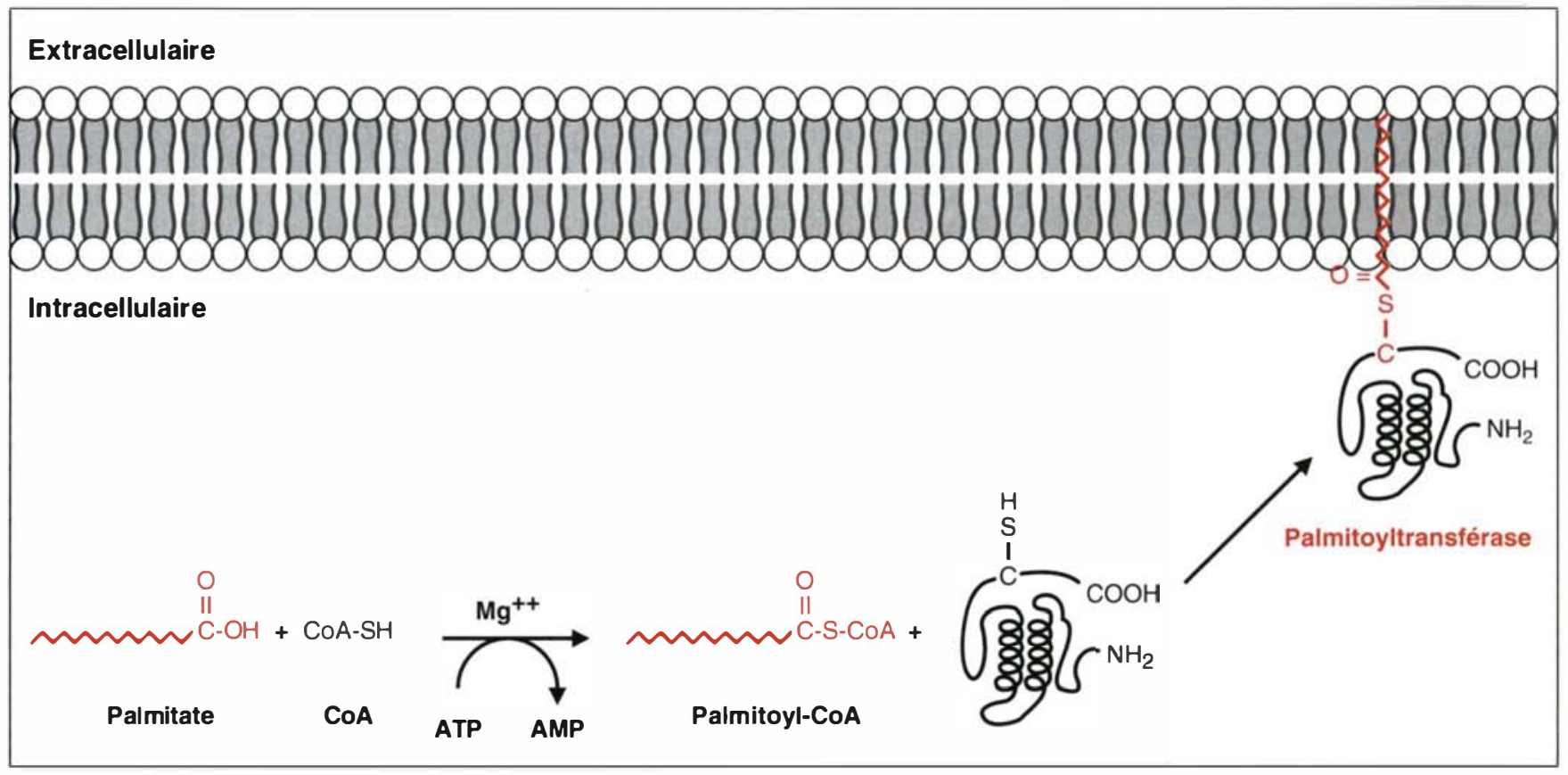

Figure 2. Palmitoylation des protéines. Pour qu'une protéine soit palmitoylée, le palmitate doit d'abord être activé en palmitoyl-coenzyme A (palmitoyl-CoA). Cette activation est effectuée par une acyl-CoA synthétase qui combine le palmitate au CoA en présence d'ATP et de magnésium. Le palmitoyl-CoA ainsi formé réagit avec les cystéines de certaines protéines par l'intermédiaire d'une palmitoyltransférase. Le palmitate est relié aux cystéines par une liaison thioester. Une fois palmitoylées, les protéines peuvent s'associer à la membrane où elles exerceront leurs actions.

caractère réversible, comme le montre la courte demi-vie de liaison du palmitate sur plusieurs protéines [19, 20]. Ainsi, la palmitoylation permettrait une association ou une dissociation rapide des protéines à la membrane plasmique. Il apparaît de plus en plus que la palmitoylation est impliquée dans de nombreux processus dynamiques de régulation des fonctions protéiques [25-27].

\section{Isoprénylation des protéines}

\section{- Synthèse d'isoprènes}

et nature de la liaison

L'isoprénylation des protéines consiste généralement en l'ajout d'un isoprène de 15 ou 20 carbones sur une cystéine située dans la région $\mathrm{C}$ terminale de certaines protéines [6,
7]. Une liaison thioéther lie les isoprènes aux cystéines et cette liaison est hydrolysable avec le nickel de Raney [28]. Les isoprènes sont issus du mévalonate (figure 3) qui, une fois activé en isoprényl pyrophosphate (5 carbones), pourra se combiner avec d'autres molécules identiques via l'action de plusieurs enzymes, dont des isoprényl-pyrophosphate synthases. Ainsi seront formés succes- 


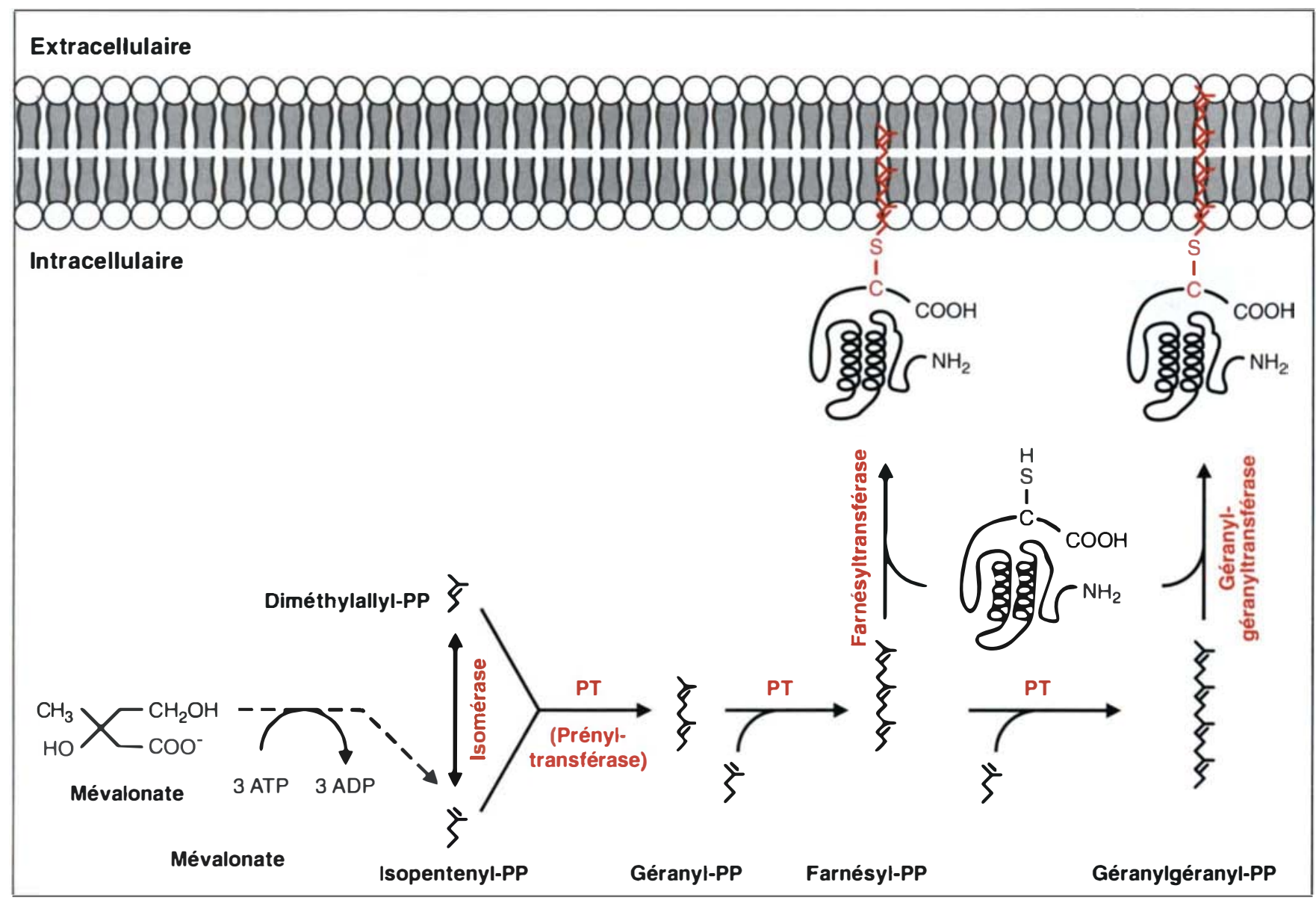

Figure 3. Isoprénylation des protéines. Les isoprènes sont tous issus du mévalonate qui est transformé en isopentényl-pyrophosphate (isopentényl-PP) à la suite d'une série de réactions impliquant trois phosphorylations consécutives. Une isomérase convertit alors l'isopentényl-PP en diméthylallyl-PP. Ces deux composés de 5 carbones se combinent sous l'action d'une prényltransférase et forment le géranyl-PP (10 carbones). Des additions subséquentes d'isopentényl-PP mènent à la formation successive du farnésyl-PP (15 carbones) et du géranylgéranyl-PP (20 carbones) qui sont les deux principales formes d'isoprènes transférées sur les protéines. Les farnésyl- et géranylgéranyltransférases reconnaissent des séquences d'acides aminés spécifiques contenant une ou deux cystéines sur lesquelles sont transférés les isoprènes. Les protéines ainsi isoprénylées peuvent alors s'associer aux membranes ou à d'autres protéines.

sivement des isoprène-pyrophosphates à $10,15,20,25$, etc. carbones [6]. Les deux espèces réactives d'isoprènes les plus répandues sont le farnésyl-pyrophosphate (15 carbones) et le géranylgéranyl-pyrophosphate (20 carbones). Il est possible que des isoprènes de plus de 20 carbones soient également transférés sur des protéines [7].

L'isoprénylation se fait exclusivement sur des protéines possédant certains motifs d'acides aminés en position C-terminale, contenant une ou deux cystéines [7]. Après isoprénylation, les protéines présentant une séquence $\mathrm{CXXX}(\mathrm{C}=\mathrm{Cys}$ et $X$ = n'importe quel acide aminé) subissent une protéolyse amenant la cystéine en position C-terminale. Celle-ci devient alors disponible pour être méthylée par une carboxyméthyltransférase de classe III [29, 30]. Dans le cas du p21Ras, la protéine ayant subi toutes ces transformations sera également palmitoylée [17] (figure 4). L'isoprénylation semble irréversible, car la demi-vie de liaison des isoprènes est sensiblement équivalente à celle des protéines modifiées. De plus, comme les produits des proto-oncogènes ras subissent une protéolyse (figure 3) entraînant la destruction du site de reconnaissance pour les isoprényltransférases [31], un recyclage de ces protéines via des étapes d'isoprénylation/déisoprénylation semble peu probable.

Les isoprényltransférases sont des enzymes cytoplasmiques qui peuvent se diviser en deux principaux types: farnésyltransférases et géranylgéranyltransférases [7]. On ne connaît qu'un type de farnésyltransférase qui réagit avec des protéines possédant un motif $\mathrm{CXXX}$, où $\mathrm{C}$ représente une cystéine et $X$ n'importe quel 


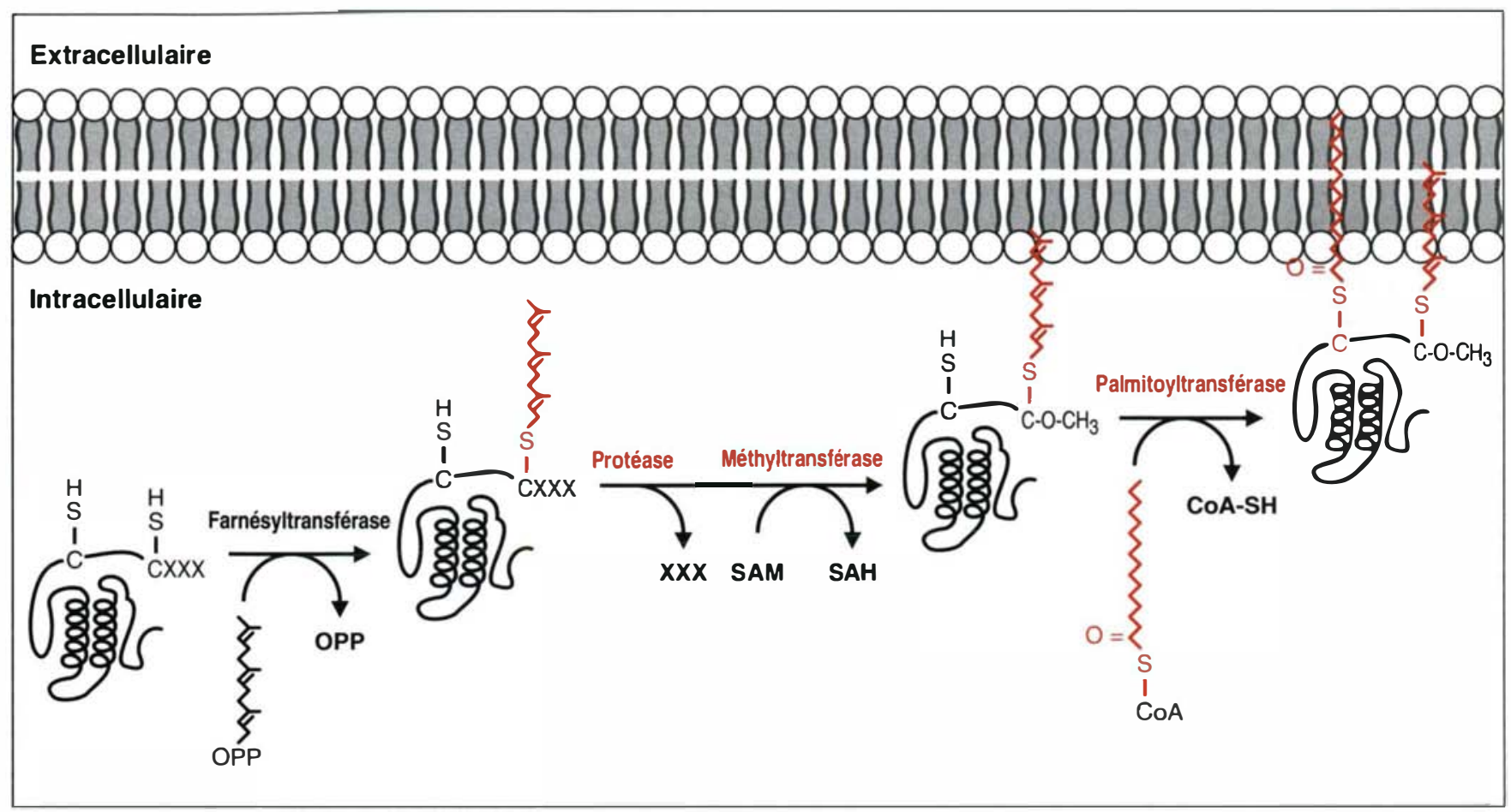

Figure 4. Modification post-traductionnelle du p21ras. Les protéines faisant partie de la grande famille des produits des protooncogènes ras subissent toutes une modification post-traductionnelle par des isoprènes. Dans certains cas, comme celui de p21Ras, la protéine est également palmitoylée. Ces deux modifications sont nécessaires à l'activité de la protéine. Une farnésyltransférase reconnaît d'abord le groupement CXXX contenu dans la région C-terminale de p21Ras et transfère un groupement farnésyl sur la cystéine. Le groupement CXXX farnésylé est alors reconnu par une protéase qui coupera les trois derniers acides aminés. La cystéine farnésylée devenue C-terminale sera à son tour reconnue par une carboxyle-méthyltransférase qui la méthyle. La protéine ainsi modifiée s'associe faiblement à la membrane plasmique et possède dès lors une faible activité. L'ajout ultérieur d'un palmitate sur une cystéine, située quelques résidus en amont, permet l'association complète avec la membrane et l'activité maximale de p21Ras. Le palmitate est soumis à un important recyclage, ce qui permet l'activation ou la désactivation rapide de la protéine. SAM = S-adénosyl-méthionine, ou AdoMet, SAH : S-adénosyl-homocystéine, ou AdoHcy.

acide aminé [7]. Cette enzyme agit sur les protéines de la famille des produits de protooncogènes ras ([17], $m / s n^{\circ} 8-9$, vol. 9, p. 996). Cependant, d'autres protéines sont également farnésylées, telles la rhodopsine kinase [32], la sous-unité $\gamma$ de la transducine [33], la sous-unité $\alpha$ de la GMPc phosphodiestérase de la rétine [34] et le facteur a de la levure [35]. La farnésyltransférase est un hétérodimère contenant des sous-unités $\alpha$ et $\beta$. La sous-unité $\beta$ lie la protéine alors que la sousunité $\alpha$ serait responsable de la liaison du farnésyl-pyrophosphate [36]. Contrairement à la farnésyltransférase, on distingue deux classes de géranylgéranyltransférases. La classe I reconnaît, comme la farnésyltransfé- rase, des protéines ayant un motif CXXX en position C-terminale [7, 37]. Parmi les protéines modifiées par cette classe de géranylgéranyltransférases, il faut souligner: la sous-unité $\gamma$ de certaines protéines $G$ trimériques [38], plusieurs membres de la famille des protéines $G$ de faible poids moléculaire comme la protéine RaplA (smg p21A) [39], et la sous-unité $\beta$ de la GMPc phosphodiestérase de la rétine [34]. La classe II reconnaît les protéines ayant un motif XCC (RablA) ou CXC (Rab3A) en position Cterminale [39]. La protéine Rab3A (smg p25A) est également carboxyleméthylée [40]. Fait intéressant, la cystéine modifiée se trouve déjà en position C-terminale. Il n'y a donc pas de protéolyse et le site de reconnaissance par l'enzyme est conservé. Il est donc possible d'émettre l'hypothèse que le transfert du géranylgéranyl catalysé par la classe II est potentiellement réversible. Comme la farnésyltransférase, les géranylgéranyltransférases sont des hétérodimères contenant des sous-unités $\alpha$ et $\beta$. De plus, il a été démontré que la farnésyltransférase et la géranylgéranyltransférase I possèdent des sousunités $\alpha$ identiques [4I].

La farnésyltransférase et la géranylgéranyltransférase de classe I catalysent toutes les deux le transfert de leur isoprène spécifique sur des protéines contenant un motif $\mathrm{CXXX}$. C'est la nature de l'acide aminé retrouvé en position $\mathrm{C}$-terminale de 
la séquence $C X X X$ qui détermine le choix de l'isoprène: si le motif CXXX se termine par un résidu Gly, Thr, His, Asn, Gln, Ser, Ala ou Cys, la protéine sera farnésylée, alors que si le motif se termine par un résidu Leu, la protéine sera géranylgéranylée; les motifs se terminant par un résidu Val, Ile, Phe et Met sont reconnus par les deux enzymes [7]. Cependant, bien que les enzymes farnésyltransférase et géranylgéranyltransférase I démontrent des préférences pour leurs isoprènes respectifs, si la concentration d'accepteurs est suffisante, les deux enzymes seront capables de catalyser le transfert de l'un ou l'autre des deux substrats [37]. Il est à noter que des études quantitatives ont permis de déterminer qu'il existe plus de protéines géranylgéranylées que farnésylées [28].

\section{- Rôles}

Les isoprènes modifient plusieurs types de protéines dont quelques exemples sont donnés dans le
Tableau III. L'isoprénylation, comme les autres modifications des protéines par des lipides, peut entraîner l'association des protéines avec la membrane plasmique $[17,38]$. L'isoprénylation semble essentielle à la survie des cellules de la rétine, puisqu'un défaut de la géranylgéranyltransférase des protéines $\mathrm{Rab}$ a été associé à une dégénérescence de la rétine [42]. L'isoprénylation est reliée au potentiel transformant de produits des protooncogènes ras. En effet, ces protéines ne posséderaient leur plein pouvoir transformant que si elles sont isoprénylées. De plus, l'expression de ces protéines oncogéniques a pu être associée à la présence de nombreux cancers chez l'humain [43]. L'isoprénylation permet également de réaliser des interactions protéine-protéine, comme c'est le cas entre la sous-unité $\gamma$ de la transducine et la métarhodopsine [33], ou entre la protéine RaplB (smg p21B) et la protéine GDS (une protéine qui favorise l'échange de nucléotides associés avec la protéine Rapl B) [44]. D'autres types d'interactions protéines-protéines relayées par les isoprènes vont sûrement être mis à jour. Le marquage utilisant du mévalonate a permis de déceler de nombreuses protéines isoprénylées, mais très peu d'entre elles ont pu être identifiées. L'isoprénylation semble aujourd'hui impliquée dans de nombreux mécanismes de régulation des fonctions cellulaires, et la recherche à ce propos est en plein essor

\section{RÉFÉRENCES}

39. Seabra MC, Goldstein JL, Sūdhof TC, Brown MS. Rab geranylgeranyl transferase: a multisubunit enzyme that prenylates GTP-binding proteins terminating in CysX-Cys or Cys-Cys. J Biol Chem 1992; 267 : 14497-503.

40. Farnsworth CC, Kawata M, Yoshida Y, Takai Y, Gelb MH, Glomset JA. C-terminus of the small GTP binding protein smg p25A contains two geranylgeranylated cysteine residues and a methyl ester. Proc Natl Acad Sci USA 1991; 88: 6196-200.

\begin{tabular}{|c|c|c|c|c|}
\hline \multicolumn{5}{|c|}{$\begin{array}{c}\text { Tableau III } \\
\text { EXEMPLES DE RÔLES JOUÉS PAR L'ISOPRÉNYLATION }\end{array}$} \\
\hline Protéine & Séquence & Isoprène & Rôle de l'isoprénylation & Référence \\
\hline $\begin{array}{l}\text { Facteur a } \\
\text { S. cerevisiae }\end{array}$ & CVIA & $F$ & $\begin{array}{l}\text { Nécessaire à l'activité biologique } \\
\text { (sécrétion normale) }\end{array}$ & [35] \\
\hline $\begin{array}{l}\text { Protéine G } \\
\text { (sous-unité } \gamma \text { ) }\end{array}$ & CAIL & G & Association à la membrane & [38] \\
\hline Lamin B2 & CLVM & ? & $\begin{array}{l}\text { Association à la membrane nucléaire } \\
\text { (nécessaire au cycle cellulaire normal) }\end{array}$ & [45] \\
\hline $\begin{array}{l}\text { Transducine } \\
\text { (sous-unité } \gamma \text { ) }\end{array}$ & CVIS & $F$ & $\begin{array}{l}\text { Augmentation du couplage avec la } \\
\text { métarhodopsine }\end{array}$ & [33] \\
\hline $\operatorname{Rab} 1 \mathrm{~A}$ & GGCC & G & $\begin{array}{l}\text { Association à la membrane } \\
\text { (transport vésiculaire)* }\end{array}$ & [40] \\
\hline Rab 3A (smg p25A) & DCAC & G & $\begin{array}{l}\text { Association à la membrane } \\
\text { (régulation des fonctions sécrétrices)* }\end{array}$ & [40] \\
\hline Rhodopsine kinase & CVLS & $\mathrm{F}$ & Stimule l'activité de phosphorylation & [32] \\
\hline $\begin{array}{l}\text { Retinal GMPc } \\
\text { phosphodiesterase } \\
\text { (sous-unité } \alpha \text { ) }\end{array}$ & $\mathrm{CClO}$ & $\mathrm{F}$ & Association à la membrane & [34] \\
\hline (sous-unité $\beta$ ) & $\mathrm{CCIL}$ & G & Association à la membrane & [34] \\
\hline
\end{tabular}

$?=$ Résultats obtenus par marquage métabolique avec le $\left[{ }^{3} \mathrm{H}\right]$-mévalonolactone.

$F=$ farnésyl. G = géranylgéranyl. * Rôle proposé.

Code à une lettre des acides aminés: A: Ala; C: Cys; D: Asp; G: Gly; : Ile; L: Leu; M: Met; Q: Gln; S: Ser; V: Val. 
41. Seabra MC, Reiss Y, Casey PJ, Brown MS, Goldstein JL. Protein and geranylgeranyl transferase share a common a subunit. Cell 1991 ; 65 : 429-34.

42. Seabra MC, Brown MS, Goldstein JL. Retinal degeneration in choroideremia: deficiency of rab geranylgeranyl transferase. Science 1993 ; 259: 377-81.

43. Newman CMH, Magee AI. Posttranslational processing of the ras superfamily of small GTP-binding proteins. Biochim Biophys Acta 1993; 1155 : 79-96.

44. Shirataki H, Kaibucchi K, Hiroyoshi M, Isomura M, Araki S, Sasaki T, Takai Y. Inhibition of the action of the stimulatory GDP/GTP exchange protein for smg p21 by the geranylgeranylated synthetic peptides designed from its C-terminal region. Biol Chem 1991 ; 266 : 20672-7.

45. Kitten GT, Nigg EA. The CAAX motif is required for isoprenylation, carboxyl methylation, and nuclear membrane association of the lamin B2. J Biol Chem 1991; 266 : 8540-4.

\section{Summary}

Post-translational modifications of proteins by lipids

Covalent modifications of proteins by lipids were first associated with a passive role in membrane anchoring. More recently, post-translational modifications of proteins by covalent lipids have been identified and they seem to have more than just a structural function. There are two types of post-translational modifications by lipids: palmitoylation and isoprenylation. The first is reversible and the modified proteins are found at the cytoplasmic face of the plasma membrane or at the endoplasmic reticulum. The second is irreversible and the modified proteins are found in almost all intracellular locations such as the cytoplasm, cell membrane and nucleus. Palmitoylation principally occurs on cysteines, but no consensus sequences have been identified, so far. Conversely, isoprenylation is found only on proteins with particular Cterminal sequences containing one or two cysteines. These two modifications were shown to be involved in the regulation of many proteins such as $\beta_{2}$-adrenergic receptor and Ras proteins. Post-translational modifications of proteins by covalent lipids appear to play an important role in the regulation of cellular functions. 